\section{A Dance of Organized Chaos}

\section{Using a Village to Run a Children's Program}

LAURA PITTS

$\mathrm{I}$

found myself laughing at the baffled faces of my library volunteers the first morning of our newly formed preschool reading time, Destination Library Tails.

I warned them that we would have a lot of people show up. These two volunteers had jumped at the chance to head an ongoing preschool reading time-one that could take place in the morning for parents with small children and for homeschool families. I was thrilled to have someone in the community who cared enough to dedicate two days a month to providing this service, especially because it would be an ongoing program. I just needed them to trust me when I said a lot of kids would show up.

I recognized a few months into my position five years ago that there was a serious need at our library to offer a story hour for preschool-age children. Providing programs during summer reading alone was not going to cut it, especially if we wanted to see the library grow with young faces eager to check out books and learn.

Over the past five years, we have been able to offer occasional storytime programs, but nothing regular. We are a small library with limited staff, and while our Friends of the Library organization is heavily involved in volunteer efforts, they can't do everything.

Having two parents offer to assist us with a program was a blessing in disguise- one that I was not going to let pass.

As with any library story hour, the programs take time to develop. Some program themes work and some dates and times do not work. Even the day's weather condition can hinder

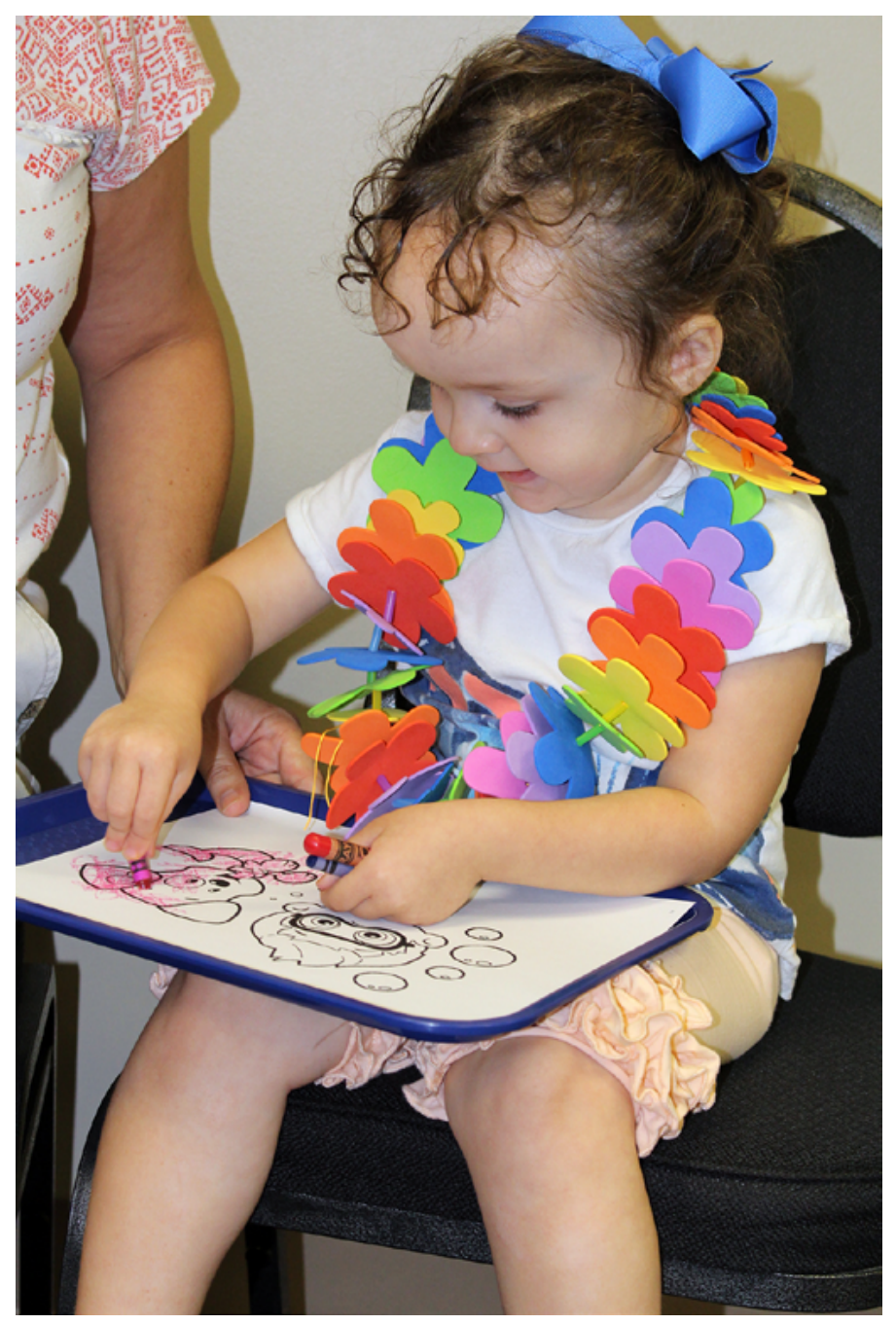

Allie practices her coloring skills.

everything, including attendance-rainy days can be full of attendees or a bust.

We created Destination Library Tails to incorporate many different levels of learning and topics to keep the interests for not only the children, but also the parents. The program is aimed at kids three years old through kindergarten, and the theme

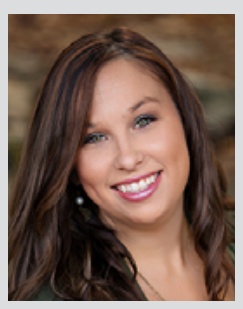

Laura Pitts is the director of the Scottsboro (AL) Public Library. 


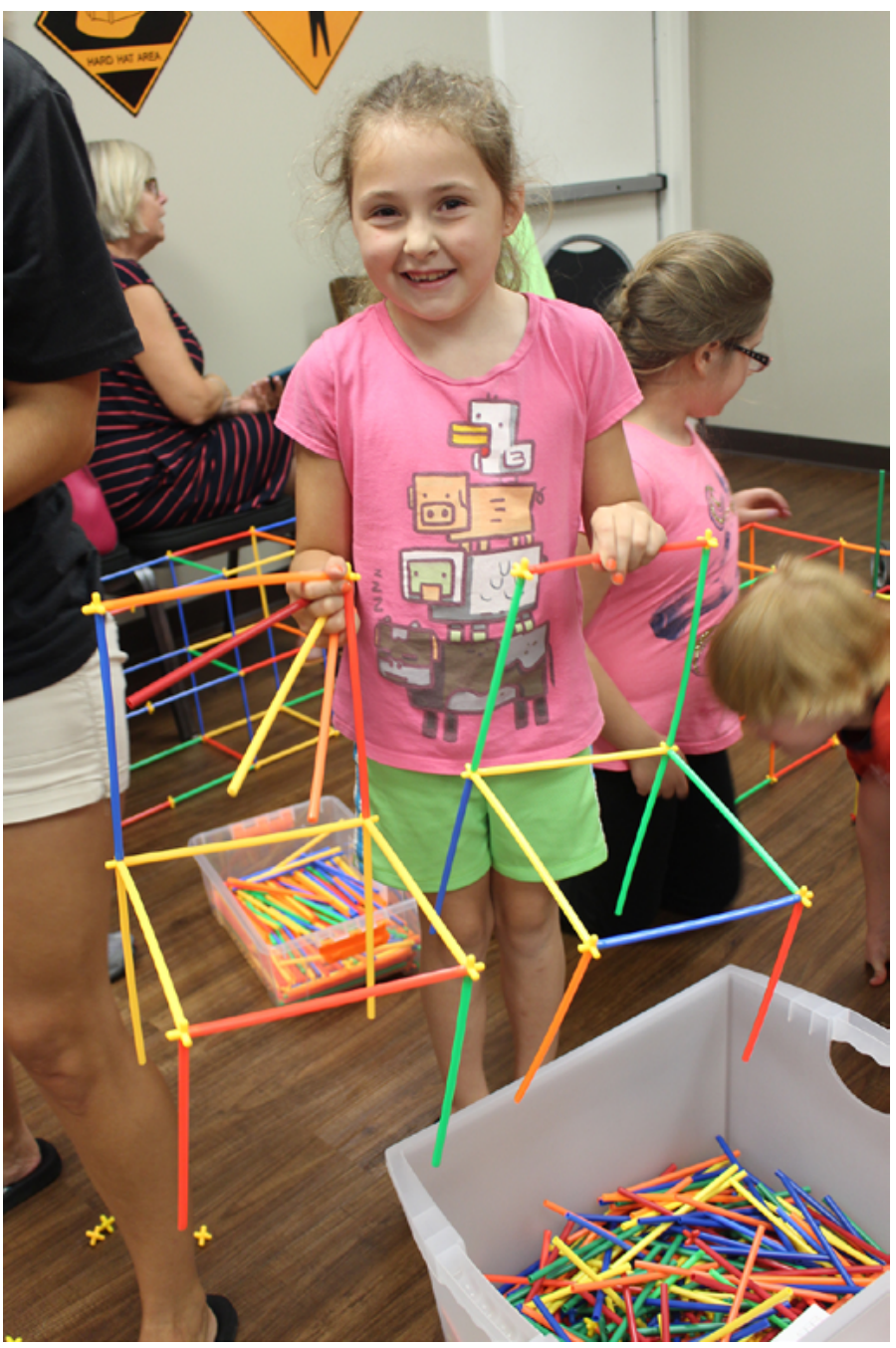

Gemma is proud of her engineering work!

centers around our children's department mascot, my yellow Labrador retriever Leonardo da Vinci.

It's through the tales of his tail that we learn about several different topics-what it means to not be a bully, how to have good manners, and my favorite, taking a summer exploration around our community. Leo is a good mascot and the children love him. That is why I knew we would have a steady group of children and parents attend the programs.

The first program was very simple-read a book, do some type of fun craft, eat a snack, and have some play time with Legos and other building blocks from our STEM lab. We used the library's Facebook page to promote the program.

The volunteers (some adults and some preteens) expected us to have ten people show up; we had sixty. "Is it always this busy during a children's program?" one of the volunteers asked. I nodded as I ran to and from, herding all the kids to the back room, clearing my throat for the reading of our story and getting ready to be a kid myself.

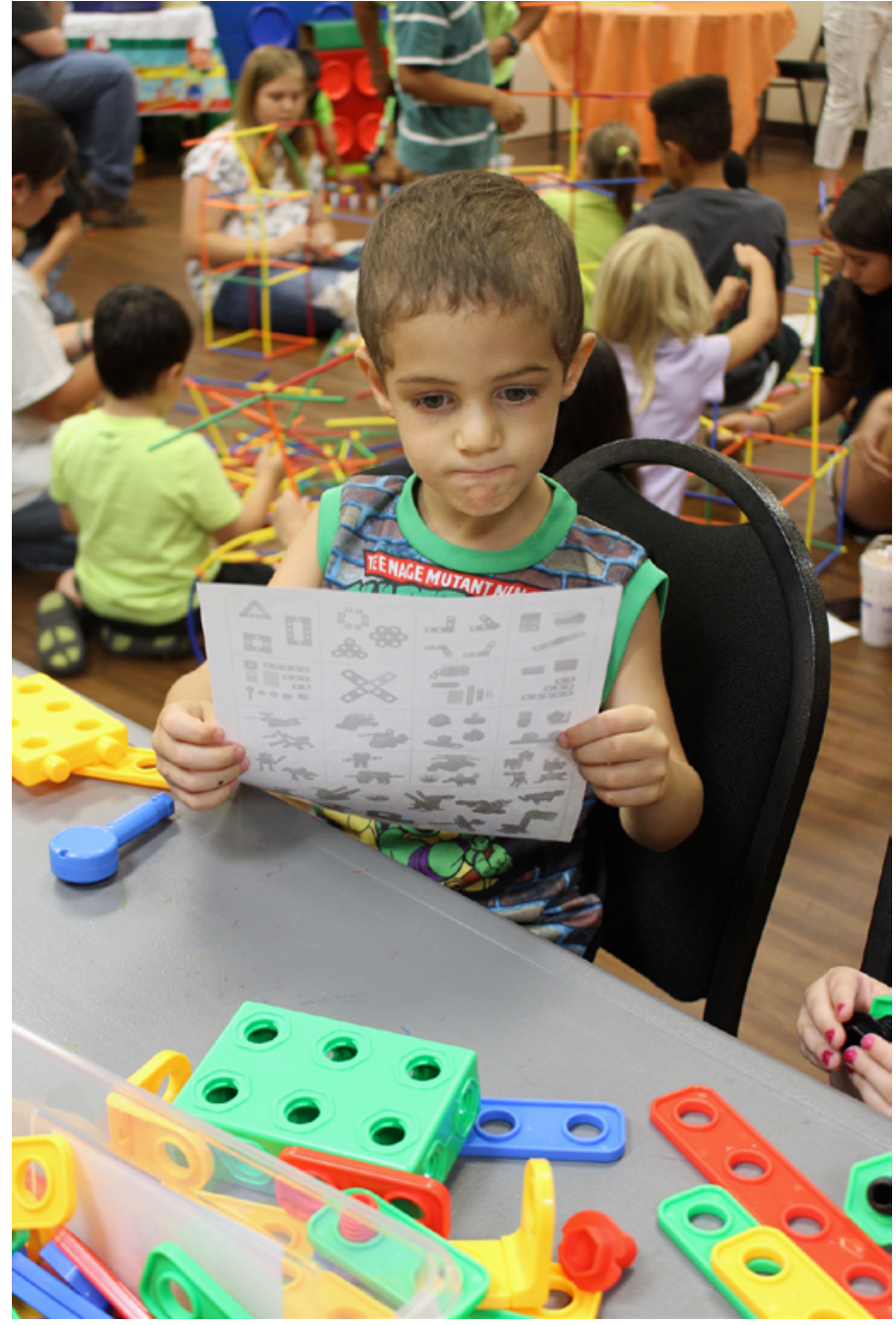

Adrien studies the plans carefully.

Then, as if everyone around me realized the importance of what we were doing, all the parents began helping as needed, working with all the children to cut and glue and create their pieces of art. Each time we meet, the parents are so helpful with the children. The dance of organized chaos is one to embrace, and when your community has as great a need as ours does for literacy programs for children, that village sure does come in handy.

\section{Calling Your Village of Volunteers}

Each community is different, but the mission we all share is to help our communities reach their potential through our programs and services. It's important to realize that if you are planning recurring programs for children you don't have to do it alone. Sometimes the need to have extra hands on deck is crucial to having people continually attend the program.

Parents are watching to see how organized you are, and the children are looking for something fresh each visit. Consider sending out a call for program volunteers, being specific about your needs. Would a former teacher or someone who is currently working part-time in a school setting be the best help? 


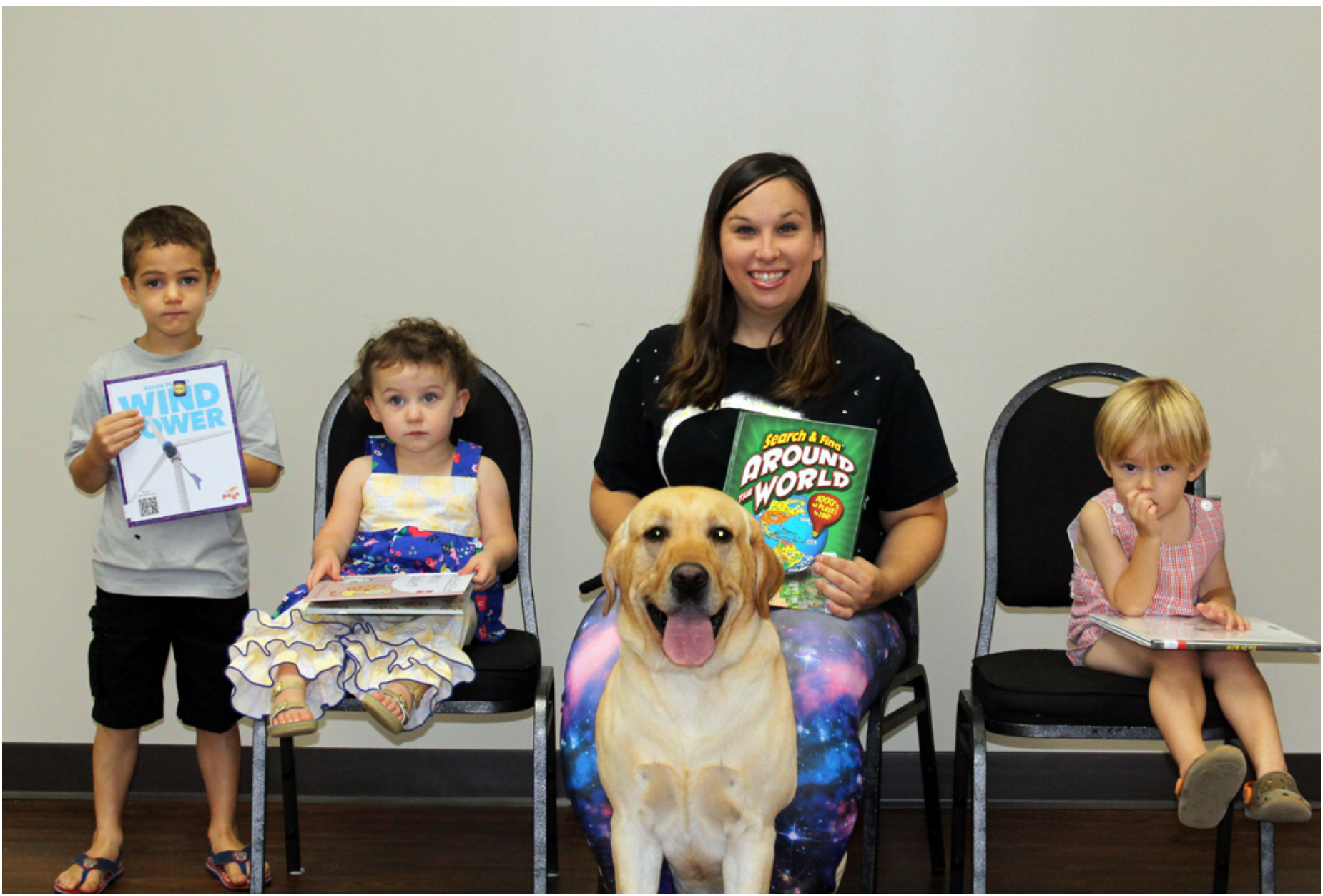

Librarian Laura Pitts poses with eager readers and man's best friend Leo.

What about that homeschool mother looking for a place to volunteer her talent? Having a good volunteer policy in place that lists certain do's and don'ts and requirements of volunteers (for example, completing a background check or having no criminal history) can help fend off the volunteers who simply will not be appropriate. Utilize your official library social media platforms and in-house fliers to spread the word.

\section{Making It All Work}

Understand that everyone brings some type of talent to the group. However, in my experience, I have learned that talent is sometimes not something you see from the outside. Occasionally you have to bring it out of people, and when you do, something beautiful develops.

The same can be said of the hidden talent of the parents and grandparents. One of your regular adults might be a very outgoing storyteller. Another adult might be extremely crafty and can help you plan activities and develop bulletin boards and fliers. You might even have an adult who works with children at a local church and will be willing to help lead fun story songs and rhymes for the kids.
Don't underestimate the power of a volunteer, especially one for a children's program. Volunteers for these types of programs mostly know what they are getting themselves into. It is no surprise to them to have a child come up with a runny nose, ask to go to the bathroom, or worse-as has happened to us beforefind that the shaving cream art project made its way from the paper to the child's skin. (Yes, that child was green for a few days, but he just got to pretend to be a dinosaur.) Volunteers, especially those who are parents or have worked with children before, know what to expect.

\section{Embracing the Chaos}

Some days, your programs are going to go exactly as you planned. Other days, your programs are going to take place, just without as many volunteers or as much help as you need. Life gets in the way sometimes. Amid the planning, figure out a way to make your volunteers feel special. A special snack can make a parent's day just as much as a new pen or a notebook.

One of the most important things is to find a way for an adult to engage in a creative activity with a child. This not only provides a time for the parent to spend quality time with the child, 


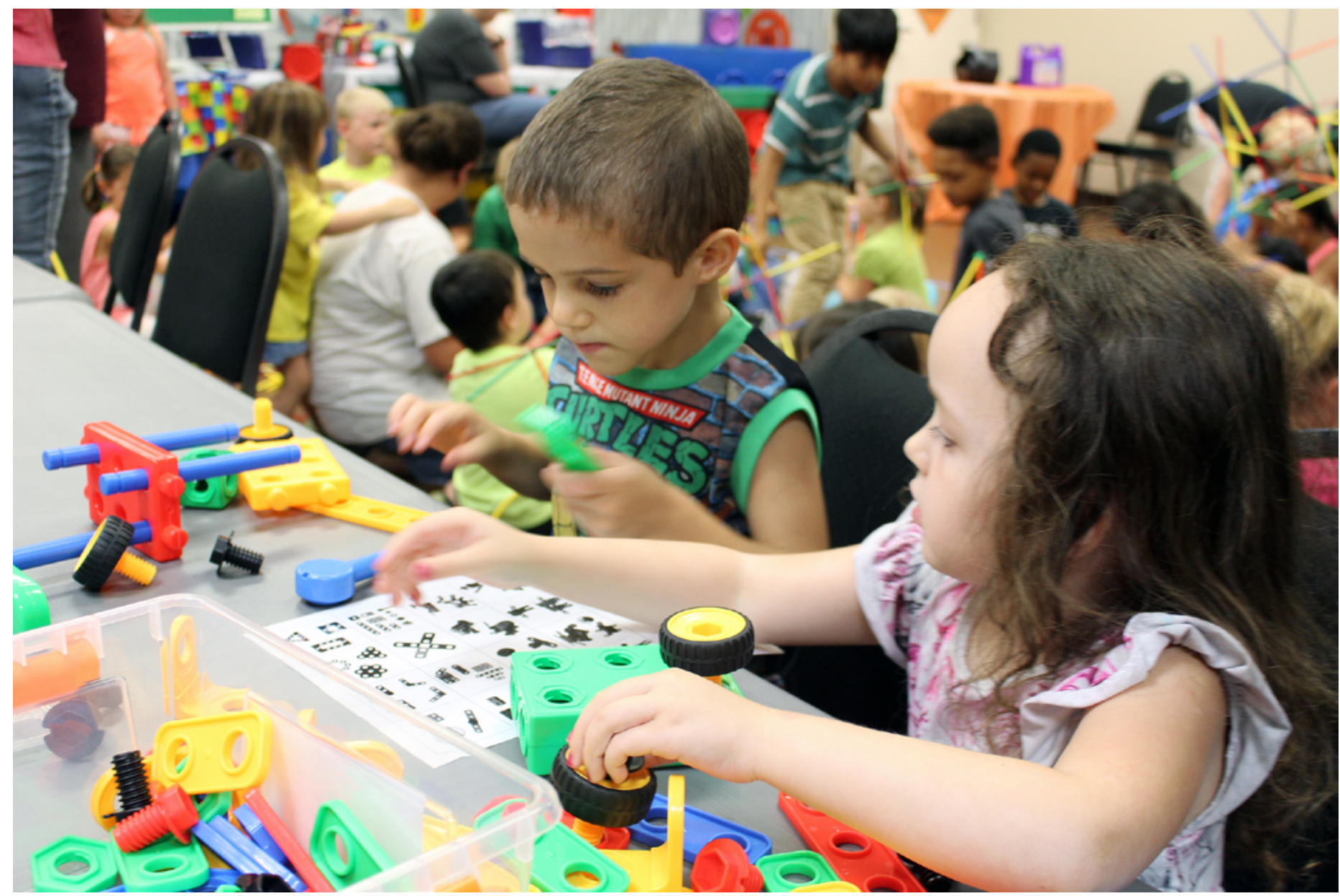

Working together is fun!

but also reinforces the idea of parent involvement that will be drilled in their heads once their child officially begins school.

Without volunteers to help us with our story times, we would be lost. They allow us to give all the children at our programs as much attention as we can.
Literacy programs for children have the power to inspire learning and creativity on so many levels. Having enough hands in the fire to provide that extra assistance makes the job even more rewarding as a librarian. It's one thing to have people attend a program, but another for them to take time out of their lives to pour into the lives of other children. Don't let those opportunities pass you by. Instead, figure out ways to nurture the volunteers you have and work hard to recruit more as needed. $\delta$.

\section{PEADINESS MATTEPS CONTINUING EDUCATION IN READINESS MAT TERS EARYY CHLLHOOD PROGRAMMING}

\section{CURRENT WORKSHOPS:}

\section{- READiness Matters}

- Techno Toddlers: App Happy or Digital Story Time

- One Shot Story Time: Designing a quality story time

\section{W. FRANK STEELY} Library
- Bilingual (Spanish/English) Story Time Basics for Bilingual and Non-Bilingual Presenters

Additional workshops available! 